\title{
NOTA SOBRE O SERVIÇO METEOROLÓGICO NO RIO GRANDE DO SUL AO LONGO DO SÉCULO XIX (NOTA DE PESQUISA)
}

\author{
GALARÇA, Paulo Jolar Pazzini - pjgalarca@yahoo.com.br \\ Centro Polar e Climático, Instituto de Geociências. \\ Universidade Federal do Rio Grande do Sul. \\ SIMÕES, Jefferson Cárdia - jefferson.simoes@ufrgs.br \\ Centro Polar e Climático, Instituto de Geociências. \\ Universidade Federal do Rio Grande do Sul.
}

\begin{abstract}
RESUMO: Análise de documentação histórica permitiu inventariar os recursos existentes para monitorar o clima durante o século XIX na Província de São Pedro do Rio Grande do Sul e no estado do Rio Grande do Sul. No inicio do século (1825) já existiam alguns trabalhos e em 1883 uma rede de 20 estações meteorológicas, montadas pela "Commisão da Barra de Rio Grande", estava operando, cobrindo parte do atual estado do Rio Grande do Sul. Este levantamento encontrou grande quantidade de informações, sobre a meteorologia no RS daquela época, que estavam perdidas, em arquivos, inclusive fora do país, por exemplo, as "Notas Meteorológicas da Commissão da Barra de Rio Grande" publicadas pelo geógrafo alemão Henry Lange.
\end{abstract}

PALAVRAS-CHAVES: Clima; Rio Grande do Sul; meteorologia; observatório.

NOTE ON WEATHER SERVICE IN RIO GRANDE DO SUL THE XIX CENTURY

ABSTRACT: historical documentation analysis allowed the inventory of existing resources to monitor the weather during the nineteenth century in the Provincia de St. Pedro do Rio Grande do Sul and in the state of Rio Grande do Sul In the beginning of the century (1825) there were some papers and. in 1883 a network of 20 weather stations, assembled by "Commisão da Barra do Rio Grande ", was operating, covering part of the current state of Rio Grande do Sul. This survey found much information on the weather in RS that time, who were lost in files, including outside the country, for example, the "Weather Notes from the Commission da Barra do Rio Grande " published by the German Henry Lange .geographer.

KEYWORDS: Climate; Rio Grande do Sul; meteorology; observatory.

\section{INTRODUÇÃO}

A literatura mais divulgada, sobre as características climáticas do Rio Grande do Sul, considera que os trabalhos observacionais iniciaram com a fundação da estação meteorológica na escola de Engenharia em Porto Alegre, no ano 1909. Portanto, em tempo cronológico, é curta a série temporal que temos para discutir um fenômeno tão complexo como o clima, mesmo na escala espacial que hoje corresponde ao território do RS.

Eventos climáticos, quando são de alta intensidade, como ondas de frio, longos períodos de precipitação ou de estiagem, trazem impacto sobre a sociedade, em especial sobre uma sociedade agropastoril, o caso do RS no século XIX.

A proposta deste levantamento foi averiguar se existiram políticas públicas ou projetos para desenvolver um serviço meteorológico como ferramenta para ajudar a defesa civil.

Inicialmente fizemos um levantamento na literatura historiográfica sobre a província e o estado o Rio Grande do Sul no século XIX, procurando entender o contexto histórico da época, fatores sociais, políticos, econômicos com o objetivo de ambientar a busca do tema deste 
trabalho $O$ passo seguinte foi à procura de obras com uma abordagem mais especializada sobre a questão ambiental, onde houvesse elementos para aplicar na climatologia histórica. 0 procedimento final foi a pesquisa em arquivos históricos á procura de documentos que tivessem informações aplicáveis à climatologia.

\section{O INICIO DA OBSERVAÇÃO METEOROLÓGICA NO RIO GRANDE DO SUL}

Até o momento, o texto mais antigo, sobre meteorologia encontrado na documentação, é aquele que consta no relatório de Camargo (1868). São comentários sobre o clima e valores sobre temperaturas médias anuais para o triênio 1825-1827. No documento não existem detalhes como o local ou locais onde os registros foram obtidos, ou explicações técnicas sobre esse serviço meteorológico.

No mesmo documento aparecem registros intitulados "Observações de Hydrometro em Porto Alegre para o mês de fevereiro de 1848", uma tabela com dados de umidade, quantidade de horas diárias de chuvas medidas em horas e medição da altura do lago Guaíba. Essa tabela não tem dados de todo o mês, somente de cinco dias.

Segundo esse documento, existia uma régua para medir a altura da água no porto da Alfândega. Este local é onde hoje se encontra a Praça da Alfândega, no centro de Porto Alegre, atualmente área seca devido a inúmeros aterros. No documento não há nenhuma informação se neste local (porto) era onde estavam os demais aparelhos meteorológicos da estação.

Ainda, nesse relatório de Camargo também consta dados de temperatura média mensal para a cidade do Rio Grande relativos ao período 1857-1861, mas também sem detalhes sobre a coleta meteorológica.

Encontramos um "Quadro estatístico com observações meteorológicas em Porto Alegre, quadros mensais de abril a setembro para o ano de 1857", onde consta o nome de José dos Santos Pereira como encarregado da estatística. Neste documento existem tabelas com dados de temperaturas, tomadas três vezes ao dia, e observações sobre as condições diárias do tempo. No texto consta que esse trabalho era feito na casa $n^{\circ} 26$ da Rua da Igreja, atual Rua Duque de Caxias, não há informações técnicas da estação e se esse local era parte de um serviço regular da administração.

Ainda sobre o serviço meteorológico em Porto Alegre, noutro documento encontramos o relatório de Fonseca (1886), vice-presidente da província do Rio Grande do Sul, encaminhado ao presidente da província Miguel Calmon Du Pin Almeida:

É de tal forma reconhecida a necessidade do estudo da athmosfera que os serviços meteorológicos são executados com todo o cuidado não só na Europa e na América do Norte como até Japão, na Índia e na Austrália.

Creada esta repartição em 1867, se então tivesse estabelecido um serviço diário regular de observação da temperatura, pressão atmosférica, humidade do ar, ventos reinantes e chuvas correspondentes a esses ventos, teríamos já um abundante material para o conhecimento do clima desta capital cuja importância não é necessária encarecer.

Um dos meus antecessores, o engenheiro Antonio de Mascarenhas Telles de Freitas obteve, em 9 de julho de 1872 na administração do Exmo Sr. Conselheiro Jeronymo Martiniano Figueira de Mello instrumentos com os quais se estabeleceu na Repartição um serviço meteorológico. 
Tendo tomado, em 1874 a direção desta repartição o engenheiro Manoel Correa da Silveira Netto que era então prof. de Physica e Chimica da Escola Militar levou esses instrumentos com os quais se estabeleceu na Repartição de Serviços Meteorológicos. Mais tarde foram recolhidos os instrumentos já inutilizados, ficando assim a repartição impossibilitada de fazer observações meteorológicas.

Conhecida, como é, a influencia do conhecimento do clima em qualquer paiz para o estudo das suas necessidades hygienicas, agrícolas e industrial me parece que a Assembléia provincial não deve hesitar em autorizar que Vsa. Ex. a fazer aquisição de instrumentos que facilitem semelhante estudo.

Para a montagem do observatório faz-se necessário que Vsa. Ex. autorise mudança desta repartição para o próprio provincial para ella construída na praça D. Pedro $2^{\circ 1}$, que hoje serve de quartel general e habitação do Ex. Sr Commandante das armas trocado por um antecessor de V. Ex. pelo pardieiro onde está alojado o quartel da policia.

A necessidade desta mudança tem sido reconhecida por todos os antecessores de $V$. Ex. desde o Exm. Sr. Desembargador Henrique Pereira Lucena.

A praça, referida no texto, é a atual Praça da Matriz e o provincial é o prédio onde atualmente está o Ministério Público do Rio Grande do Sul, conhecido pelo apelido de "Forte Apache" situado na esquina da Rua Jerônimo Coelho com a referida praça, no bairro Centro.

\section{O REGISTRO METEOROLÓgICO REGULAR}

$\mathrm{Na}$ documentação consultada existem inúmeras notas sobre meteorologia ou pequenas anotações, muitas vezes feitas por particulares. No entanto, questiona-se a existência, num determinado momento, de um projeto reconhecidamente oficial instituído pela administração da época.

Encontramos uma ação que apresenta essa última característica, a série produzida pela "Commisão da Barra do Rio Grande" no período 1877-1887, sob a direção do engenheiro Lopo Neto. Neste documento estão registradas as temperaturas médias anuais e total de precipitação anual para a cidade do Rio Grande. No entanto, os dados de precipitação são apenas para o período $1883-1887$.

Sobre este trabalho, Azambuja (1891) comenta que o geógrafo alemão Henry Lange publicou na Deutsche Rundschau für Geographic und Statistic (número de outubro de 1889) um artigo sobre a meteorologia do Brasil, onde cita o trabalho da "Comissão" e afirma que notou erros nos dados, notificando o autor (Honório Bicalho).

$\mathrm{Na}$ cidade de Pelotas existia o "Observatório meteorológico da Commisão de Terras e Colonização" (Azambuja, 1892), órgão encarregado da regularização de terras em função da chegada de imigrantes, principalmente. Os documentos consultados não dão detalhes sobre este trabalho, como a localização do observatório, equipamentos e o período total de funcionamento.

Azambuja (1892) cita somente dados do observatório para o ano de 1887 (janeiro a agosto), apresentado uma tabela com temperaturas mensais médias, máximas e mínimas, total de dias de chuva, e total de precipitação.

\footnotetext{
${ }^{1}$ Atual Praça da Matriz, localizada no bairro Centro.
} 
Na cidade de Porto Alegre, em 1892, foi inaugurado o "Observatório da Secretaria de Obras Publicas" sob a direção do engenheiro Afonso Herbert. Azambuja (1893) comenta que José Antonio Leal Coelho (fiscal da estrada de ferro no RS) elogiou os equipamentos desse observatório, afirmando que era na época um dos melhores do Brasil.

Este observatório estava localizado no torreão norte de edifício existente ainda hoje junto a Praça Marechal Deodoro (atual Praça da Matriz, Centro) na esquina da rua Jerônimo Coelho com o largo João Amorim de Albuquerque.

Azambuja (1893, 1899,1902) apresenta tabelas com dados de temperatura média mensal, precipitação total mensal, pressão atmosférica mensal, até o ano de1900.

Azambuja (1894) comenta que a estação estava $12 \mathrm{~m}$ acima do terreno; $35 \mathrm{~m}$ acima do nível médio das águas do lago Guaíba; e desabrigado de qualquer edifício numa circunferência de raio superior a $60 \mathrm{~m}$ (Figura 1 ). Ele ainda relata que:

Não é possível dar-se com precisão a altitude do observatório por não se ter feito os respectivos estudos, entretanto admitimos por conjecturas, a altitude de $40 \mathrm{~m}$ para a posição dos barômetros a que suppomos não se afastar muito da verdadeira; tornando assim de algum valor scientífico as pressões indicadas.

O observatório funciona desde junho, tendo sido publicadas regularmente as observações desde $1^{\circ}$ de julho. A fim de corresponder ao que foi determinado pelo congresso internacional meteorológico, brevemente serão encetadas observações no mesmo momento physico estipulado; isto é $12 \mathrm{~h}$ Greenwich que corresponde aqui a $3 \mathrm{~h} 24$ $m 48,8 \mathrm{~s}$.

O observatório possue apparelhos registradores e apparelhos comuns. Os apparelhos registradores constam 1 barometro metálico, 1 thermomentro, grande modelo, 1 psychometro, 1 higrometro, 1 actinometro, 1 anemoscopio, 1 anemometro, pluviometro, 1 electrometro de Mascarat - Aparelhos simples - 2 barometros de fortin, 1 aneroide de Dollond, 4 thermometros de max e min, sistema six, 1 thermometro de Negretti e Zambra, 1 nevoscopio e 1 aparelho para ozonometria.[...\} O barômetro de mercúrio registrador, grande modelo, ainda não pode funcionar por terem chegado quebrados não só os tubos primittivos como os dois extras ultimamente recebidos. .

Foi feita nova encomenda de outros dois tubos, recomendando-se perfeito acondicionamento e a menor baldeação possível.

O electrometro de Mascart, aparelho importante, também ainda não começou a funcionar por falta de peças que chegaram quebradas.

Uma das dificuldades com que aqui se luta é com a falta de uma oficina de concertos de apparelhos de precisão sactisfatoriamente montado. A hora medida da capital continua a ser dada diariamente.

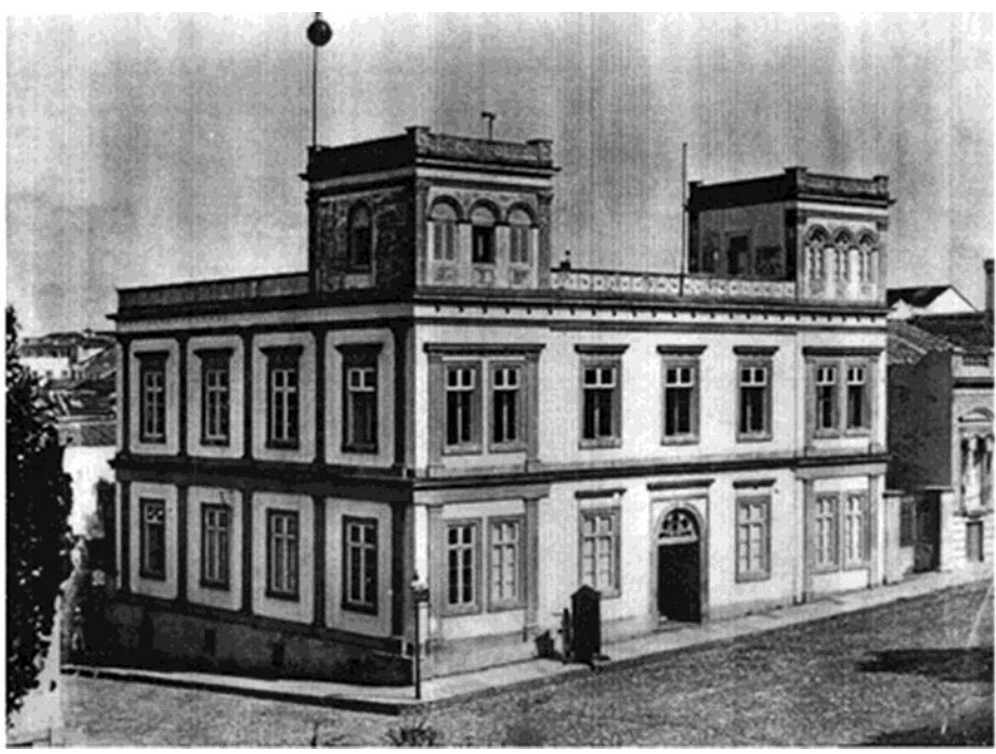

Figura 1- Prédio na praça Marechal Deodoro (Praça da Matriz) no centro de Porto Alegre onde localizavase a estação meteorológica "Secretaria de Obras Publicas" entre 1893 e 1914. 
O mesmo autor também comenta que era monitorada a altura do lago Guaíba:

Anexo a este serviço de observações mandou-se collocar um mareometro devidamente escalado, no trapiche da companhia de luz electrica, a fim de ser tomada diariamente a altura das águas do rio Guayba e assim conhecer-se exactamente os níveis máximos, mínimos e médios de suas águas.

O local referido é a companhia Fiat Lux, cujo prédio estava na esquina da rua Sete de Setembro com a João Manoel (bairro Centro) e onde atualmente é área seca devido aos aterros. Os documentos encontrados, até o momento, não trazem nenhum dado quantitativo sobre estas medições.

\section{A REDE METEOROLÓGICA}

Em 1874, o barão de Capanema (diretor do "Serviço Nacional Telegráfico") organizou uma rede nacional usando as instalações telegráficas. Na província de São Pedro do Rio Grande do Sul apenas Porto Alegre recebeu equipamentos dessa ação, em 1876, segundo Beschoren (1989) esse projeto não se desenvolveu.

A primeira rede meteorológica na então Província do Rio Grande do Sul parece ser aquela da "Commisão da Barra de Rio Grande" proposta em 1883.

Os aparelhos foram colocados nas estações telegráficas das seguintes cidades: Alegrete, Arroio Grande, Bagé, Caçapava, Cruz Alta, Conceição do Arroio ${ }^{2}$, Cacimbinhas, ${ }^{3}$ Cachoeira do Sul, Itaqui, Jaguarão, Livramento, Pelotas, Piratini, Porto Alegre, São Borja, São Gabriel, Santa Maria, Torres, Triunfo, Uruguaiana (AZAMBUJA, 1887).

Cada observatório recebeu um termômetro de máxima e mínima (de Six) fabricado por Negretti\&Zambra, um barômetro aneroide de Casella, e um pluviômetro com "aprovette" graduada de Casella.

Sobre a qualidade desses equipamentos Azambuja (1887) faz o seguinte comentário:

Alem disso releva dizer que para obter dados seguros ou de confiança seria necessário dotar as estações com instrumentos melhores que aquelles que the foram fornecidos. A cada estação, como dissemos, foi fornecido um thermometro de máxima e minima. Mas os thermometros de six não gozam de boa reputação, e quando se quer observações regulares é forçoso ter um thermometro para as máximas e outro para as mínimas. O barômetro, quando

\footnotetext{
${ }^{2}$ Atual município de Osório.

${ }^{3}$ Atual município de Pinheiro Machado.
} 
for aneróide, deve ser um aneróide de primeira qualidade. Um psychrometro de Augusto também é indispensável

Azambuja (1891) relata que os dados registrados começaram a ser organizados em 1885, mas com problemas de qualidade devido a erros de leitura. A "Commisão", em função disso, fez um treinamento dos técnicos distribuindo desenhos explicativos de como fazer a leitura dos instrumentos. Na documentação, consultada por nós, aparecem dados quantitativos provenientes dessa rede apenas para o ano de 1877.

Lindman (1974) citou, em 1893, que o observatório da "Commisão da Barra de Rio Grande" recebia, há muitos anos, contribuição das 20 estações citadas acima. Assim, podemos deduzir que até o final do século XIX, temos 17 anos de observações meteorológicas do Rio Grande do Sul produzidas por essa rede. Até o momento ainda não encontramos os dados dessas séries temporais (com exceção de 1877).

No entanto, Azambuja (1891) comenta que os dados do observatório de Porto Alegre não eram fornecidos à "Commisão de Melhoramentos da Barra de Rio Grande", apesar dos dados serem enviados telegraficamente para o Rio de Janeiro, e no passado eram divulgados inclusive nos jornais de Porto Alegre.

\section{PROJETOS PARTICULARES}

Além dos projetos oficiais citados, havia trabalhos particulares, mas a documentação não esclarece se forneciam sistematicamente dados para a administração pública. Entre eles destacamos o trabalho do engenheiro alemão Maximiliano Beschoren que registrou dados de diversas localidades: Santo Antonio da Palmeira (1879-1880); Passo Fundo (1880-1881); Santo Ângelo (1871); São Luiz Gonzaga (1879-1886).

Beschoren não era remunerado como meteorologista, trabalhava como agrimensor e na cidade onde residia temporariamente montava um observatório. Ele mantinha colaboração com a "Commisão da Barra de Rio Grande" e recebeu desta, conforme suas notas, equipamentos para complementar sua estação: um pluviômetro (Casella), um termômetro de máxima e mínima (Negretti Zaneak) e um aneroide (Casella). Ele comenta que a Comissão deu a ele acesso aos dados da série 1877-1885.

Azambuja (1888) comenta sobre um observatório meteorológico instalado em Uruguaiana, de propriedade da empresa inglesa Brazil Great Southern, que explorava a linha ferroviária Rio Grande-Bagé. Este observatório não fornecia dados para a "Commisão da Barra de Rio Grande", apesar de inúmeros pedidos.

Os dados do observatório da Brazil Great Southern, para o ano de 1888, foram publicados no boletim da Sociedade de Imigração do Rio de Janeiro e reproduzidos no "Annuário da Província do Rio Grande Sul" (1888).

O fiscal de estrada de ferro José Antonio Leal fez observações locais, em Cachoeira do Sul segundo Azambuja (1893), o qual cita dados de precipitação total mensal e temperatura média mensal para o período 1890 - 1891. Os documentos não esclarecem se as observações 
meteorológicas de Leal eram ou não um trabalho oficial, ou seja, se ele além de fiscal também era responsável por um serviço meteorológico.

Em 1893 começou a funcionar em Pelotas o observatório fundado no "Lyceu de Ciências Agronômicas", inicialmente dirigido pelo prof. Guilherme Minsen, e que funcionou até 1913. O jornal editado na cidade de Pelotas, Diário Popular, publicava regularmente o boletim meteorológico deste observatório.

Lindman (1974) comenta a existência de dados meteorológicos provenientes de uma longa observação para Agudo (município de Santo Ângelo), mas não especifica que período e a extensão dessa série, apenas que os dados eram enviados para serem publicados no Koseritz Deustche Zeitung, jornal de língua alemã editado em Porto Alegre pelo doutor Carlos von Koseritz.

No livro de Lindman são encontradas as temperaturas médias mensais em Agudo somente para o ano de 1891. Também não temos informações se estes dados eram inseridos no serviço oficial.

O fiscal da estrada de ferro Júlio Antonio Vasques fez observações em Taquara em 1890 e 1891, e em São Francisco de Paula em 1892. Vasques relata que devido a sua transferência para outra cidade, essas observações foram continuadas por Jordelino G. de Serra, juiz de direito das duas comarcas (AZAMBUJA 1893). Também não encontramos informações se Vasques era oficialmente encarregado do serviço meteorológico.

Para Santa Cruz do Sul existem dados de temperatura média mensal e precipitação total mensal para os anos 1899 e 1900, extraídos do jornal local Die Kolonie de Santa Cruz. O documento não traz nenhuma informação sobre os anos de funcionamento deste observatório, por quem era administrado e se contribuía para a estatística oficial. (AZAMBUJA 1902)

\section{CONCLUSÃO}

Após a avaliação da literatura sobre a província e o estado do Rio Grande do Sul, no século XIX, constatamos que a historiografia está bem construída sobre fatos sociais, como economia, migração, revoluções, etc., mas raras são as publicações sobre o clima do Rio Grande do Sul daquela época.

As informações que eventualmente aparecem que, podem ser relacionadas à climatologia histórica, são relativas a eventos extremos como grandes enchentes causadoras de, na época, prejuízos materiais e risco para setores da população.

Essas informações, com raras exceções, aparecem sem nenhuma nota meteorológica, apenas com dados de escala baseada na destruição ocorrida.

Neste trabalho, com a documentação distribuída em diversos arquivos, o sistema de catalogação é precário e dificulta a procura e os dados não se encontram numa categoria especifica, sendo difícil saber se aquele "ofício" ou "comunicação" é único ou é parte de uma correspondência mais longa e detalhada. 
$\mathrm{Na}$ consulta de publicações em nível nacional também constatamos poucas informações, por exemplo, Neto (2001) no seu texto sobre 24 séries produzidas em diversas partes do Brasil, abrangendo parte do século XVIII e século XIX, cita para o Rio Grande do Sul apenas os dados de Maximiliano Beschoren.

É evidente que o inicio da implantação de um serviço meteorológico, pela administração pública, ocorreu em função dos trabalhos para melhoria do porto da cidade do Rio Grande. O porto era fundamental economicamente não só para a cidade do Rio Grande como para toda província. As condições de navegação eram extremamente perigosas como comenta Alves (2008), segundo ele havia na época varias discussões e pressões para o começo de um trabalho de engenharia no canal de Rio Grande que era muito instável.

Para exemplificar esta questão existe o episódio do naufrágio do navio a vapor Rio Apa, que fazia a linha entre Rio de Janeiro, e Montevidéu, surpreendido por uma violenta tempestade em 11 de julho de 1887, episódio este relatado na obra de Christina Helena Barboza (2006).

No seu trabalho consta que este desastre, do qual não houve sobreviventes, causou uma comoção nacional. A imprensa da época criticou o governo exigindo a urgente criação de uma rede nacional de meteorologia. Ela comenta que o observatório Nacional do Rio de Janeiro tinha colocado em curso, em 1886, um projeto da criação de uma rede nacional, mas este projeto não se desenvolveu.

Quanto aos demais projetos, aqui relatados, quanto à sua aplicabilidade é outro tema que precisa de mais dados para ser esclarecido. Por exemplo, qual o objetivo do "Observatório meteorológico da Commisão de Terras e Colonização"? Deduzimos que seja para aplicar na navegação e agricultura, mas até o momento não temos dados para afirmar isso.

Sobre o projeto da criação de uma rede nacional, não encontramos informações que demonstrem uma relação estreita disso com o trabalho que havia no Rio Grande do Sul. Por exemplo, na observação de Azambuja (1891) que os dados de Porto Alegre não estavam sendo enviados para a "Commisão da Barra de Rio Grande" e sim telegraficamente para o Rio de Janeiro, parece indicar que esta ação estava ligada a um projeto nacional, mas não há, na documentação consultada, nenhuma informação.

Alguns dos documentos examinados mostram manifestações de funcionários da administração pública, da época, com conhecimento da importância da meteorologia, O comentário de Fonseca (1886) enfatiza essa questão.

Até o momento não foi possível criar um organograma para saber qual o órgão diretamente ligado ao serviço meteorológico, nas diferentes épocas, e qual a sua posição na administração publica da província ou do estado.

Por outro lado, ficou claro que um serviço que estava bastante envolvido na organização e divulgação destes dados era o estatístico. Por exemplo, na obra "De Província de São Pedro ao Estado do Rio Grande do Sul" está o ofício encaminhado por José Pedro César, em janeiro de 1831, ao presidente da província descrevendo as dificuldades, como falta de ajudantes e desconfiança dos informantes. Num outro documento, de 1833, ele relata: 
A dificuldade dos meios para conseguir os dados, particularmente geográficos e os relativos à parte natural, deve-se ao fato de haver necessidade de trabalhos muito detalhados, viagens a lugares distantes e de difícil acesso, com despesas consideráveis. Como exemplo registra-se o fato que para se saber qual a temperatura de determinado lugar, havia a necessidade de se deslocarem até o local para fazer a medição da temperatura média, e essa observação deveria ocorrer pelo menos durante 20 anos para que se tivesse certeza do fato, resultando dessa forma, uma estatística imperfeita, porque, na falta dessa observação direta, era necessário recorrer a obras antigas ou ao conhecimento de algum cidadão ilustre da época.

No ano de 1854, o novo governador, José Marcelino da Rocha Cabral, enfrentou as mesmas dificuldades. Entre 1835 e 1845 o serviço parou completamente devido à Revolução Farroupilha. Ainda consultamos a FEE (Fundação Estadual de Economia e Estatística do Rio Grande do Sul) procurando material sobre meteorologia no século XIX, fomos informados que no banco de dados não existem documentos sobre este assunto.

No trabalho de campo procuramos dados na memória histórica material. A maioria dos locais onde foram registradas observações meteorológicas, no século XIX, estão descaracterizados. Grande parte dos prédios, onde havia algum tipo de serviço meteorológico, não existem mais. Se preservado, não existe memória histórica nestes locais sobre o serviço meteorológico no passado.

Por exemplo, o local onde funcionou o "Observatório das Obras Públicas" na Praça Marechal Deodoro, o prédio está restaurado e mantém suas características arquitetônicas originais, atualmente no local funciona o Ministério Público do Estado do Rio Grande do Sul. Os historiadores locais não tem informações sobre os detalhes do observatório.

\section{REFERÊNCIAS BIBLIOGRÁFICAS}

ARQUIVO DO ESTADO DO RIO GRANDE DO SUL. Observações thermométricas no mês de abril feitas na casa $n^{\circ} \mathbf{2 6 1}$ da rua da Igreja. Encarregado da estatística - José dos Santos Pereira Maço 2 - Quadro estatístico com observações meteorológicas em Porto Alegre, quadros mensais de abril a setembro de 1857. Estatística avulsa e códices.

AZAMBuJA, G. A. Annuario do Estado do Rio Grande do Sul para o Anno de 1891. Porto Alegre: Gundlach, 1891.

AZAMBUJA, G. A. Annuario do Estado do Rio Grande do Sul para o Anno de 1892. Porto Alegre: Gundlach, 1892.

AZAMBujA, G. A. Annuario do Estado do Rio Grande do Sul para o Anno de 1893. Porto Alegre: Gundlach, 1893.

AZAMBUJA, G. A. Annuario do Estado do Rio Grande do Sul para o Anno de 1894. Porto Alegre: Gundlach, 1894.

AZAMBUjA, G. A. Annuario do Estado do Rio Grande do Sul para o Anno de 1899. Porto Alegre: Gundlach, 1899.

AZAMBuJA, G. A. Annuario do Estado do Rio Grande do Sul para o Anno de 1902. Porto Alegre: Gundlach, 1902. 
Barboza, Christina Helena História da Meteorologia no Brasil (1887 - 1917). Congresso Brasileiro de Meteorologia - Edição IV - Florianópolis, 2006.

BESCHOREN, M. Impressões de viagem na província do Rio Grande do Sul. Trad. E. M. Bergmann e W. Rauber. Porto Alegre: Martins Livreiro, 1989.

CAMARgo, E. Quadro Estatístico e Geográfico da Província de São Pedro do Rio Grande do Sul. Porto Alegre, 1868.

FONSECA, M.D. Relatório apresentado ao presidente da Província Miguel Calmon du Pin Almeida, 1886.

FUndAÇÃO DE ECONOMIA E ESTATÍSTICA. De Província de São Pedro a Estado do Rio Grande do Sul, Censos do RS 1803-1950. Porto Alegre, 1984.

LINDMAN, C. A. M. A Vegetação do Rio Grande do Sul. Belo Horizonte: Itatiaia; São Paulo: EDUSP, 1974.

MINSEN, G. Contribuição para o estudo da climatologia do Rio Grande do Sul. Observações meteorológicas feitas durante o período de 1893 a 1902 . Pelotas: Livraria Universal de Nechenique Irmãos \&. Pelotas, 1902?

SANT'ANNA NETO, J. L. História da Climatologia no Brasil: gênese, paradigmas e a construção de uma Geografia do Clima. Tese de Livre-Docência. Presidente Prudente: FCT/UNESP, 2001. 